\title{
IMPACT OF PERFECTIONISIM, SOCIAL SUPPORT AND GENDER ON ACHIEVEMENT MOTIVATION OF ADOLESCENTS
}

KEY WORDS: Gender,

Perfectionism, Social Support, Achievement Motivation and Adolescents.

\section{Dr. V. Tirumala} Rao*

\section{Dr. V. Srikanth} Reddy
ICSSR- Post Doctoral Fellow, Dept. of Psychology, S.V. University, Tirupati-517 502. *Corresponding Author

Professor, Dept. of Psychology, S.V.University,Tirupati-517 502.

E 1 An attempt was made in the present investigation impact of perfectionism, social support and gender on achievement motivation of adolescents. Sample of the present study consists of 400 adolescent subjects in Andhra Pradesh state. Perfectionism developed by Slaney et al (1996), Perceived Social Support Scale developed by Dahlem, Zimet, Walker, (1991) and achievement motivation scale designed by Pratibha Deo and Asha Mohan (1985) were administered. Results revealed significant impact of perfectionism, social support and gender with regard to achievement motivation.

\section{INTRODUCTION}

Adolescence has been described as a transitional stage with uncertain boundaries. In other words, it is difficult to tell exactly at what ages adolescence begins or ends-its inception and termination is difficult to determine. Basically characteristics component of adolescence mark the beginning and ending of key factors of development.

Perfectionism refers a belief that perfection should be strived for. In its pathological form, it is a belief that anything less than perfect is unacceptable. This is often considered an unhealthy belief.

Social support is often used in a broad sense, including social integration. However, Social integration refers to the structure and quantity of social relationships, such as the size and density of networks and the frequency of interaction. Social support, in contrast, refers to the function and quality of social relationships, such as perceived availability of help or support actually received.

Achievement Motivation referred to as the need for achievement, is an important determinant of aspiration, effort, and persistence when an individual expects his performance will be evaluated in relation to some standard of excellence. Such behaviour is called achievement-oriented.

\section{Review of Literature}

Abrol (1977) concluded that a significant and positive correlation of moderate value was found between achievement motivation and scholastic achievement. Gupta (1978) found that boys were found to possess more achievement motivation than girls. Chauhan (1984) revealed that community, sex and intelligence did not interact significantly in relation to the achievement motivation of students. Ahluwalia (1985) found that there were no significant influence boys and girls with regard to achievement motivation of children. Rani (1992) examined that girls were higher than boys in achievement motivation. Mishra (2007) studied on achievement motivation and academic performance of children; results found that boys are more achievement motivation oriented compared to girls. Bari (2008) concluded that the sex difference in Achievement motivation was also not significant impact on achievement motivation of boys and girls. Putri's (2014) stated that social support is positively and significantly related to achievement motivation. Srivastava \& Naveen Pant (2015) indicated the results showed that social support and achievement motivation was higher in females as compared to males. YuanLi, JijunLan and ChengtingJu and ChengtingJu (2015) examined both the mediation effects of achievement motivation and attribution style on the relationship between perfectionism and subjective well-being of students. Correlation analysis indicated that perfectionism was positively correlated with achievement motivation.

\section{Objective}

1. To assess the impact of perfectionism, social support and gender on achievement motivation of adolescents.

\section{Hypotheses}

1. There would be significant impact of perfectionism on achievement motivation of adolescents.

2. There would be significant impact of social support on achievement motivation of adolescents.

3. There would be significant impact of gender on achievement motivation of adolescents.

\section{Sample}

Sample for the present study consists of 400 adolescent subjects in Andhra Pradesh State. The subjects were in the age group of 16-19 years selected and using stratified random sampling method.

\section{Variables Studied \\ Independent Variables \\ 1. Perfectionism \\ 2. Social Support \\ 3. Gender}

\section{Dependent Variable}

1.Achievement Motivation

\section{Tools Used:}

\section{Assessment of Almost Perfect Scale:}

The APS-R (Slaney et al 1996) provided the measure of perfectionism in this study. It consists of 23 items with 7-point scale. The reliability for the scale was found to be 0.91 using test-retest method.

\section{Assessment of Social support:}

Social support scale developed by Dahlem, Zimet and Walker, (1991). It consists of 12-item with 7-point scale. The reliability for the scale was found to be 0.86 using test-retest method.

\section{Assessment of Achievement Motivation:}

The tool designed by Pratibha Deo and Asha Mohan (1985) it consists of 50 items with five alternative responses. The reliability for the scale was found to be 0.76 using test-retest method.

\section{STATISTICAL ANALYSIS}

The obtained data was analyzed statistically in order to test the hypotheses using Means, SD's and Analysis of Variance. 


\section{RESULTS AND DISCUSSION}

Table-I: Means and SDs for scores on achievement motivation of adolescents.

\begin{tabular}{|c|c|c|c|c|c|}
\hline Gender & \multicolumn{4}{|c|}{ Perfectionism } \\
\cline { 3 - 6 } & & \multicolumn{2}{|c}{ Low } & \multicolumn{2}{c|}{ High } \\
\cline { 3 - 6 } & & Social Support & \multicolumn{2}{c|}{ Social Support } \\
\cline { 3 - 6 } & & Poor & Good & Poor & Good \\
\hline \multirow{2}{*}{ Male } & Mean & $\mathbf{1 3 3 . 8 2}$ & 137.70 & 142.80 & 145.20 \\
\cline { 2 - 6 } & SD & 20.84 & 16.28 & 17.57 & 18.51 \\
\hline Female & Mean & 143.56 & 145.22 & 142.82 & $\mathbf{1 4 6 . 4 0}$ \\
\cline { 2 - 6 } & SD & 17.84 & 16.92 & 17.32 & 17.21 \\
\hline
\end{tabular}

\section{Grand Means}

Low Perfectionism $=$ Poor Social Support $=$ Male $=$ (M:140.07)

High Perfectionism (M:140.75)

(M:139.88)

$=(\mathrm{M}: 144.30)$

on achievement motivation of adolescents. As ' $F$ ' value is significant, hypothesis-2, which predicted that social support would significantly influence achievement motivation of adolescents is accepted as warranted by the results. Students with good Social Support ( $M=143.63)$ have good achievement motivation than the students with poor Social Support $(\mathrm{M}=140.75)$.

The probable reason might be social support works in opening doors as well as encouraging students to take risks and express their creativity as well as ability in classroom affairs. Social Support students are more likely to showcase optimistic and motivated attitude of learning and classroom affairs. In general, good social support person perceives himself to be socially competent, emotionally mature, intellectually adequate, successful, satisfied, decisive, optimistic, independent, self-reliant, self-assured, forward moving, fairly assertive and having leadership qualities. So, only the students with good social support can be motivated academically well than the students with poor social support. The results of the present study corroborates with the earlier findings of Putri's (2014) which states that social support is positively and significantly related to achievement motivation. social support and male obtained a low mean score of 133.82 indicate their poor achievement motivation compared to other groups.

In terms of Perfectionism, students with high Perfectionism $(\mathrm{M}=144.30)$ have good achievement motivation than the students with low Perfectionism ( $\mathrm{M}=140.07)$. In terms of Social Support, students with good Social Support $(M=143.63)$ have good achievement motivation than the students with poor Social Support ( $\mathrm{M}=140.75)$. In terms of gender, Female $(\mathrm{M}=144.50)$ have good achievement motivation than male $(\mathrm{M}=139.88)$.

Table-II: Summary of ANOVA for scores on achievement motivation of adolescents.

\begin{tabular}{|l|l|l|l|l|}
\hline $\begin{array}{l}\text { Source of } \\
\text { Variance }\end{array}$ & $\begin{array}{l}\text { Sum of } \\
\text { Squares }\end{array}$ & df & MSS & F-Values \\
\hline Perfectionism (A) & 435.690 & 1 & 435.690 & $7.37 * *$ \\
\hline Social Support (B) & 392.040 & 1 & 392.040 & $6.63 *$ \\
\hline Gender (C) & 299.690 & 1 & 299.690 & $5.06 *$ \\
\hline A X B & 410.760 & 1 & 410.760 & $6.95 * *$ \\
\hline A X C & 322.010 & 1 & 322.010 & $5.45^{*}$ \\
\hline B X C & 373.960 & 1 & 373.960 & $6.32 *$ \\
\hline A X B X C & 460.000 & 1 & 460.000 & $7.78 * *$ \\
\hline Within & 23176.216 & 392 & 59.123 & -- \\
\hline Total & 25456.370 & 399 & -- & -- \\
\hline
\end{tabular}

**-Significant at 0.01 level *-Significant at 0.05 level

\section{Hypothesis-1: There would be significant impact of} perfectionism on achievement motivation of adolescents. It is evident from the table-II that obtained ' $F$ ' value of 7.37 is significant at 0.01 level implying that Perfectionism has significant impact on achievement motivation of adolescents. As ' $F$ ' value is significant, hypothesis- 1 , which predicted that Perfectionism would significantly influence achievement motivation of adolescents is accepted as warranted by the results. Students with high Perfectionism ( $\mathrm{M}=144.30)$ have good achievement motivation than the students with low Perfectionism ( $\mathrm{M}=140.07)$.

The results of the present study corroborates with the earlier findings of YuanLi, JijunLan and ChengtingJu (2015) and Chenqping XU (2016) which states that Perfectionism is positively and significantly related to achievement motivation.

Hypothesis-2: There would be significant impact of social support on achievement motivation of adolescents.

Table-II shows that obtained ' $F$ ' value of 6.63 is significant at 0.05 level implying that social support has significant impact

Hypothesis-3: There would be significant impact of gender on achievement motivation of adolescents.

From the table-III that obtained ' $F$ ' value of 7.37 is significant at 0.01 level implying that gender has significant impact on achievement motivation of adolescents. As ' $F$ ' value is significant, hypothesis-3, which predicted that gender would significantly influence achievement motivation of adolescents is accepted as warranted by the results. Female $(\mathrm{M}=144.50)$ have good achievement motivation than male $(\mathrm{M}=139.88)$.

The tendency to take more responsibility for success than for failure, adaptive nature for maintaining confidence and selfworth resulting into development of better self-esteem might have helped the girls to well motivate academically. Boys should be given more opportunities and atmosphere to share their emotions and desires freely, so that they can to solve their problems and get better achievement motivated. Proper guidance and counselling services pertaining to how to get motivated should be provided to them. Moreover, workshops and seminars should be organised in all educational institutions to guide the boys about the various techniques of making achieved.

The results of the present study corroborates with the earlier findings of Abrol (1977), Gupta (1978), Rani (1992), Mishra (2007), Srivastava \& Naveen Pant (2015) which states that gender is positively and significantly related to achievement motivation.

The results of the present study contradicts with the earlier findings of Chauhan (1984), Ahluwalia (1985), Bari (2008) which states that gender is negatively and not significantly related to achievement motivation.

Data reveals that ' $F$ ' values for the first order interaction between i.e., perfectionism X social support (AXB) 6.95; perfectionism $X$ gender (AXC) 5.45 and social support $X$ gender (BXC) 6.32 and second order interaction among perfectionism $X$ social support $X$ gender (AXBXC) 7.78 are significant in causing the effect on achievement motivation of adolescents.

\section{CONCLUSIONS}

1. There is significant impact of perfectionism on achievement motivation of adolescents. Adolescents with high Perfectionism have good achievement motivation than the adolescents with low Perfectionism.

2. There is significant impact of social support on 
achievement motivation of adolescents. Adolescents with good social support have good achievement motivation than the adolescents with poor Social Support.

3. There is significant impact of gender on achievement motivation of adolescents. Female have good achievement motivation than male.

\section{REFERENCES}

1. Abrol, D. N. (1977): A study of Achievement Motivation in relation to Intelligence, Vocational interest.

2. Ahluwalia, I. (1985): A Study of Factors Affecting Achievement Motivation. In M.B.Buch (Ed.) Fourth survey of Research in Education, New Delhi, Pp: 333.

3. Bari, W. (2008). Achievement Motive and Academic Achievement of School leavers in relations to sex and school type. Unpublished M.Ed.Dissertation in Education, University of North Bengal.

4. Chauhan, S. S. (1984): A comparative study of the Achievement Motivation of scheduled Tribe and Scheduled Caste students of Himachal Pradesh in relation to their Intelligence and Socio-economic status. Fourth survey of Research in Education, New Delhi, Pp:354,355

5. Gupta (1989). A Comparative Study between Male and Female Adolescent School going Students on Emotional Maturity and Achievement in Curricular and Co-curricular Activities. Fifth Survey of Educational Research, New Delhi: NCERT.

6. Mishra. H.P. (2007). Achievement Motivation of Secondary School Students in Murshidabad District of West Bengal. International Journal of Peace, Education and Development, 5(1): 15-23.

7. Putri's (2014). The relationship between peer social support and academic resilience of young adult migrant students in Jakarta. International Journal of Education, 13(2), Pp: 1.9.

8. Srivastava. SK. \& Naveen Pant (2015). Social Support and Achievement Motivation among Adolescents. International Journal of Humanities, Arts, Medicine and Sciences, 3, (12), Pp: 117-124.

9. YuanLi, JijunLan, ChengtingJu and ChengtingJu (2015). Achievement motivation and attributional style as mediators between perfectionism and subjective well-being in Chinese university students. Personality and Individual Differences, 79, Pp: 146-151. 